Open Access

\title{
Why rapid urbanization process cannot improve employment absorption capacity of service industry in China-also on the interactive mode innovation between service industry development with urbanization under the background of transformation and upgrading
}

Shi-hong Zeng ${ }^{1,2^{*}}$ and Jie-chang $\mathrm{Xia}^{2}$

\footnotetext{
*Correspondence: sdzshh@163.com 'School of Business, Hunan University of Science and Technology, TaoYuan Road, Yuhu District, Xiangtan, Hunan Province 411201, China

${ }^{2}$ National Academy of Economic Strategy, CASS, Beijing 110102, China
}

\begin{abstract}
Background: China is experiencing rapid urbanization and service industrial developement.

Methods: In this paper, the relationship between urbanization and service employment is studied by using mathematical model and econometric test method.

Results: This paper documents that there is a significant positive correlation between rapid urbanization process and services absorbing employment ability by the regression result using time-series data since China's reform and opening up. China's urbanization process cannot become the Granger causes that service employment absorption capacity to improve by analyzing the SVAR model and Granger causality test.
\end{abstract}

Conclusions: So, Chinese urbanization patterns should transform from rapid industry park construction to increased service employment density of city.

Keywords: Service employment absorption capacity, Transformation of urban functions, Service employment density of the city

\section{Background}

It is an interesting story about the mutual development of China's service industry and urbanization. On the one hand, there are two indicators that can be used to measure the process of urbanization, the growth rate of urban built-up area and the urban employment proportion growth, and the former $(9.74 \%)$ is significantly higher than the latter $(3.13 \%)$, suggesting that the city's enclosure movement is the main performance of China's rapid urbanization and urbanization employment absorption lags behind the urban area expansion. On the other hand, China's rapid urbanization does not significantly raise the share of employment absorption in service industry, well expressed by

(C) 2016 Zeng and Xia. Open Access This article is distributed under the terms of the Creative Commons Attribution 4.0 International License (http://creativecommons.org/licenses/by/4.0/), which permits unrestricted use, distribution, and reproduction in any medium, provided you give appropriate credit to the original author(s) and the source, provide a link to the Creative Commons license, and indicate if changes were made. 
the employment proportion in three industries. For instance, at the end of 2013, the employment proportion of China's tertiary industry is $38.5 \%$, which is obviously lower than the average employment absorption level of industrialized countries and regions in the mid and late periods. If the main purpose of China's urbanization is to absorb surplus rural labor force, then the current situation shows that there exists remarkable non-virtuous interaction between the model of China's present urbanization and modern service industry development.

Though modern service industries, compared with traditional agriculture and manufacturing, have relatively higher employment elasticity, what exactly causes the reality of relatively lower employment absorption capacity in China's service industries? Throughout the research literatures, recording the effect factors of employment absorption capacity in service industry, the current controversy is mainly focused on the following two aspects. One is whether the relatively lower productivity is the cause to increase the share of employment in services. The other is whether China's urbanization process and the development of service industry follow the laws of co-evolution.

\section{Whether the relatively lower productivity causes the high proportion of employment in services}

Based on Baumol's (1967) classical theory, service industries have been absorbing pool for surplus labor because of their relatively lower labor productivity, which mainly features that the share of real output of services remains relatively unchanged, while that of employment has relatively increased. However, with higher elasticity in income demand and lower elasticity in price demand, the supply price of services can be much higher, and people will pay more cost to enjoy service, thus reflecting the "cost disease" in service industry. But, Baumol's theoretical hypothesis is questioned by many scholars. Mostly, they maintain that it is against the real economy to say service industries have relatively lower labor productivity and they are only used for the final consumption. Thus, the precondition of his theoretical hypothesis cannot demonstrate reality well.

On the contrary, Liang and Zhang (2013) think the lagging growth of labor productivity in services may decline its employment proportion. However, the demand income elasticity, given any value, would always improve service employment proportion because it can strengthen its market competitiveness to relatively enhance service labor productivity, thus increasing its market share and employment proportion. The reason for the improvement of employment proportion is not the lagging growth of productivity but the increase of demand effect of income. As a result, increasing salary income is good for raising service proportion further.

\section{Whether China's urbanization process and the development of service industry follow the laws of co-evolution}

In the course of China's economic development, the rate of China's urbanization is relatively lower than that of developed countries and regions, but after the implementation of the policy of China's reform and opening up, especially for the latest 10 years, China's urbanization has been significantly accelerating. So, what drives China's urbanization? Through the regression analysis, Liu (2007) finds out that the employment proportion of China's service industry is highly correlated with urbanization rate and the fast speed of the 
development of China's service industry has promoted the acceleration of urbanization process. Especially in the mid and late industrialization, the promotion of urbanization mainly depends on service development, thus becoming an indispensable propulsion for urbanization growth.

But also, some scholars (Hu et al. 2010) maintain that since China's reform and opening up, the 30-year urbanization's impact on the service employment has deviated from the general laws of development of urbanization and services in western developed countries and the typical facts are as follows. The contribution degrees of China's urbanization rate to employment proportion change, urban population scale index to labor productivity changes, and urban residents' per capita disposable income to value increase changes of service industry are negative.

From the point of research methods, most literatures mainly adopt the static regression equation to test the relevant relationship between the employment absorption and various exogenous variables, such as income level, urbanization rate, and the rate of industrialization, thus having ignored the casual relationship and mutual dynamic effect of China's service productivity, employment, and urbanization (He et al. 2009). In view of the existing controversy and the shortage of research methods, this paper is to illustrate the inter-activeness of time and space between China's urbanization and service employment absorption capacity through applying the structure vector auto-regression (SVAR) model, based on the relevant literatures about service industry and urban development, integrating the typical story of specific employment of service industry coming apart with urbanization in the process of China's economic development, thus further showing what China should do to innovate the interactive model between service industry and urbanization under the background of transformation and upgrading.

\section{The theory analysis of how the urbanization process influences the service employment absorption}

Reasons for service employment being able to gather in large- and medium-sized cities

The late industrialization has witnessed a large scale of service employment gathering into cities of European and American developed countries (Audretsch et al. 2011). The main reason is that, in the late industrialization, the important changes of production organization have led to a huge demand for modern services and relevant changes of space distribution of manufacture and service industry (Huallacháin 1989). Production organization changes are mainly in the following three aspects. First, the way of production organization is increasingly fragmented. The labor division should be done in accordance with comparative advantage of production value chains, so that some service links can be stripped away from the production process of traditional industry, thus transforming into producer services ( $\mathrm{Li}$ 2013). Second, the production organization process becomes more and more informatization. Production links are done by reference to the requirements of refinement operation. That the production process has realized intelligent and real-time monitoring has given rise to information, computer data processing, and software service industry. Third, it is becoming more expensive for operating cost of production. The expansion of production capacity has increased the cost of production factors, such as urban labor, land, resources, and environment; traditional processing and manufacturing links have transferred to new 
medium- and small-sized cities for their lower comprehensive cost. Technologyknowledge-intensive service industry has replaced traditional manufacturing, gathered in large- and medium-sized cities and evolved into headquarters economy (Li and Qian 2007).

The changes happened in exchange, and consumption patterns have also significantly driven service employment to gather into large- and medium-sized cities. As the urban population and income level of urban residents increased, people call for a higher requirement and quality of non-basic public services, namely, urban education, health care, culture, environment, and pension, which is beneficial to consumer services, professional and technical services, and other social services to gather into cities (Andreosso and Jacobson 2009). The rising of e-commerce and the change of shopping ways of urban residents have also driven the transition of traditional postal transportation to modern logistics and its gathering into large- and medium-sized cities. Government deregulation and financial model innovation are more beneficial for increasing the various demands of urban residents for financial insurance services.

Standing on the supplying level, there are also some good factors for preferential orientation of service enterprises in urban network (Yang 2003). Industry life cycle theory shows that production process has experienced technological change, which would change the comparative advantage of enterprises, and at that time, enterprises will gather in a professional cluster, which is more conducive to pursue economics of scale (Francisco and Kaboski 2012). Because there exists network labor division in professional cluster, such kind of network labor division bears remarkable external economy of supply, demand, and knowledge, and externality is more conducive for enterprises to conduct value chain management operation and innovation, thus decreasing production and marketing costs and increasing comparative competence advantage.

Specialized industrial cluster calls for more professional labor. As analyzed above, the change of production organization ways, exchange, and consumption ways will lead to the ways of production, exchange, and consumption to be service oriented. The increased demand for professional labor in specialized industrial cluster mostly refers to the demand for technology-knowledge-intensive service labor, including every service labor of professional and technical, such as R \& D design, marketing, warehouse, logistics, accounting, management, consulting, after-sales service, and information service.

Based on the above theoretical analysis, we can get the following theoretical propositions.

Proposition 1: Essentially, the rapid urbanization is the result of changes in industrial production, exchange, and consumption, while the tertiary industrialization of production, exchange, and consumption will promote more service employment gathering into largeand medium-sized cities.

\section{How does urbanization affect the service employment?}

From the point of long period of China's economic growth, urbanization has significantly driven structure transformation. Then, what is the internal mechanism for urbanization to drive structure change? Michaels et al. (2012) established a simple mathematical model of urbanization and structure transition, and the basic conclusion of such model is that employment transformation from agriculture sector to non-agriculture sector owns to the labor demand elasticity, higher growth of labor productivity, and higher land dependence 
of agriculture. Hence, with the development of labor productivity level and income level, agricultural activities are gathering to rural areas with lower population density, while non-agricultural activities are grouping into urban areas with larger population density. However, the shortage of such model is that it has not explained why there exists coordinative evolution between service development and urbanization. We might as well demonstrate this coordinative evolution by using a simple mathematical induction.

By the conclusion of proposition 1, it can be assumed that the output of each department needs service as the intermediate input, namely, each department output is the function of service intermediate input. Assume that each department production function is CobbDouglas production function, and that is $y_{i}=P_{i} e_{i}^{\alpha} n_{i}^{\beta}$, and $e_{i}$ is labor input of department, $n_{i}$ is land input, $P_{i}$ is labor productivity, and $\alpha, \beta$ respectively stands for the share of labor input and land input. Conducting a simple algebraic transformation to the above production function, it gives:

$$
\frac{\hat{y}_{i}}{y_{i}}=\frac{\hat{P}_{i}}{P_{i}}+\alpha \frac{\hat{e}_{i}}{e_{i}}+\beta \frac{\hat{n}_{i}}{n_{i}}
$$

or

$$
\frac{\hat{y}_{i}}{y_{i}}-\frac{\hat{P}_{i}}{P_{i}}=\alpha \frac{\hat{e}_{i}}{e_{i}}+\beta \frac{\hat{n}_{i}}{n_{i}}
$$

Substitute $\hat{p} / p=\hat{y} / y$-êe into Eq. (2), this gives:

$$
\frac{\hat{e}_{i}}{e_{i}}=\frac{\beta}{(1-\alpha)} \frac{\hat{n}_{i}}{n_{i}}
$$

Denoting $c_{i}=\frac{e_{i}}{n_{i}}$, which means population density of land area per unit, and assuming higher population density of the production department, the faster urbanization is required. Through simple algebraic operation, it gives:

$$
\frac{\hat{c}_{i}}{c_{i}}=\frac{\hat{e}_{i}}{e_{i}}-\frac{\hat{n}_{i}}{n_{i}},
$$

So, it is:

$$
\frac{\hat{e}_{i}}{e_{i}}=\left[\frac{-\beta}{1-(\alpha+\beta)}\right] \frac{\hat{c}_{i}}{c_{i}}
$$

From Eq. (5), we know:

$$
\frac{\partial\left(\hat{e}_{i} / e_{i}\right)}{\partial\left(\hat{c}_{i} / c_{i}\right)}=\frac{-\beta}{1-(\alpha+\beta)}
$$

From Eq. (6), it shows when $\alpha+\beta>1$, we get $\frac{\partial\left(\hat{e}_{i} / e_{i}\right)}{\partial\left(\hat{c}_{i} / c_{i}\right)}>0$; when $1>\alpha+\beta>0$, we get $\frac{\partial\left(\hat{e}_{i} / e_{i}\right)}{\partial\left(\hat{c}_{i} / c_{i}\right)}<0$, which means if department production function is at the stage of the increasing scale return, there exists positive correlation between employment growth of this department and the required urbanization process or urbanization rate and vice versa. Therefore, we can obtain the following proposition.

Proposition 2: It needs to be matched with the rapid urbanization or higher urbanization level to develop technology-knowledge-intensive services of increasing return 
to scale. And, the rapid urbanization is able to absorb the surplus labor, separated from traditional agriculture and manufacturing owing to the growth of labor productivity.

Based on proposition 1 and proposition 2, the rest part of this paper is mostly to test whether the development of China's service industry matches with the rapid urbanization process.

\section{Descriptive statistics}

The employment proportion evolution in China's manufacture, agriculture, and service industries

Table 1 shows the descriptive statistics of the changes of employment proportion in China's agriculture, manufacture, and service industries, being represented separately by ESHARE1, ESHARE2, and ESHARE3.

It shows that the highest standard deviation of employment proportion lies in agriculture and the lowest one is manufacture, which means that the largest change of employment proportion happens in agriculture (35.7\%), the next one is in services $(23.5 \%)$, and the smallest change is in manufacture (12.2\%). So, the employment growth of services is mainly from agriculture surplus labor.

\section{The relationship between China's urbanization and service employment}

In order to match with previous theoretical model analysis, the growth speed of urban population density is used to test China's urbanization process and observe the relationship between China's urbanization and service employment, instead of taking the general international practice of urban population proportion as the testing variation, which mostly lies in the large welfare effects implied in the current household registration system of China. For one thing, employees, being in the household register of big cities, can enjoy the institutional welfare, namely, education, health, and pension. Therefore, in big cities, especially in such cities with special resources, parts of urban employees are removed outside of the urban population statistical caliber because of the household registration system barriers (Zhang et al. 2013). For another, due to the great demolition interest implied in the current Chinese rural land ownership's transfer system, parts of urban employees with rural household registration do not want to give up their present registration to be a member of urban population in the course of industrialization and urbanization. What is more, some with urban household registration would use every possible relation to convert to their original

Table 1 The descriptive statistics of the changes in China's agriculture, manufacturing, and services from 1978 to 2013 (unit: \%)

\begin{tabular}{llll}
\hline Statistics value & ESHARE1 & ESHARE2 & ESHARE3 \\
\hline The mean & 54.23235 & 22.43824 & 23.32941 \\
The median & 53.25000 & 22.35000 & 23.9000 \\
The maximum & 70.5000 & 29.5000 & 35.7000 \\
The minimum & 34.8000 & 17.3000 & 12.2000 \\
The SD & 10.18786 & 3.032252 & 7.41004 \\
Skewness & -0.134688 & 0.475809 & 0.050213 \\
Kurtosis & 2.057947 & 3.017309 & 1.662814 \\
Sample number & 36 & 36 & 36 \\
\hline
\end{tabular}

Data source: the authors calculate the results by the original data in China Statistical Yearbooks 
rural household registration, which makes it lower for urban employees taking household registration as statistical caliber and also declines the growth of urbanization measured by the proportion of urban population (Zeng and Xiang, 2013).

Using the growth rate of urban population density to measure China's urbanization has not only overcome the effects of household registration to urban employees statistics but also considered the negative effects of simply using urban built-up area to measure urbanization, which has reflected not only the change of urban population scale but also the growth of urbanization level. As a result, only the urbanization with increasing urban population density can embody the coordinative evolution between urbanization and industrialization. If the growth rate of urban population density (LNURBDP) is used to measure the relationship of China's urbanization and service employment, by testing, the correlation coefficient of these two is $0.34, R^{2}=0.56$, and generally, this correlation is positive. However, through descriptive statistics to the change rate of China's urban population density and service employment proportion, we could know China's urbanization (7.19\%) is significantly higher than the increasing speed of service employment proportion, shown in Table 2.

Through descriptive statistics to the employment proportion of China's tertiary industry and the evolution of China's urbanization, we can obtain the following initial conclusion: there exists positive correlation between China's urbanization and service employment. But, from the mean and standard deviation shown in Table 2, we could know the servitization of China's industrial structure is remarkably behind China's urbanization.

The next step is to explore what kind of inherent causality is being existed between the absorption capacity of service employment and urbanization from the experimental level and theoretically further demonstrate why China's urbanization could not improve the service absorption capacity. Finally, this paper would state why servitization of China's industrial structure is significantly behind the process of urbanization by adopting international comparison.

\section{Empirical test}

\section{Testing method}

It is generally not enough for economic theory to do a rigorous mathematical deviation to the dynamic association between variables. The second part of this paper has just done a simple mathematical deviation to demonstrate the effect of urbanization on the

Table 2 The descriptive statistics of the change rate of urban population density and that of service employment proportion in China from 1978 to 2013 (unit: \%)

\begin{tabular}{lll}
\hline Statistics & LNURBDP & ESHARE3 \\
\hline The mean & 7.191171 & 3.169534 \\
The median & 1.968747 & 2.639296 \\
The maximum & 157.2414 & 11.80124 \\
The minimum & -39.05579 & -0.740741 \\
The SD & 32.08735 & 2.482270 \\
Skewness & 3.394799 & 1.439001 \\
Kurtosis & 17.39919 & 5.864691 \\
Sample number & 36 & 36 \\
\hline
\end{tabular}

Data source: the authors calculate the results by the original data in China Statistical Yearbooks 
improvement of service employment absorption capacity but not to establish a dynamic mathematical model to illustrate the dynamic association between these two variables. In order to empirically test the mutual dynamic influence between the improvement of the absorption capacity of China's services and the process of urbanization, the structure vector auto-regression (SVAR) model would be adopted because VAR model is usually used to forecast the mutual associated time-series system and analyze the dynamic impact of stochastic disturbance to variable system, thus revealing the influence of every economic shock to economic variables. However, we cannot get the exact form of the correlation between variables from this VAR model. Such correlation was hidden in the structural relationships of unexplainable error terms of stochastic disturbance, while the SVAR model can cover the shortage of VAR model better (Gao 2005).

Assume that there exists mutual influence among stochastic disturbances and SVAR(p) of p order among these three variables given like this:

$$
B_{0 y_{t}}=\Gamma_{0}+\Gamma_{1} y_{t-1}+\Gamma_{2} y_{t-2}+\cdots+\Gamma_{p} y_{t-p}+\mu_{t}, \quad t=1,2, \cdots T
$$

Equation (7) gives the variable matrix and parameter short constraint matrix:

$$
\begin{aligned}
& y_{t}=\left[\begin{array}{c}
\ln (\text { URBDP })_{t} \\
\ln (\text { ESHARE3 })
\end{array}\right] B_{0}=\left[\begin{array}{cc}
1 & b_{12} \\
b_{21} & 1
\end{array}\right] \Gamma_{0}=\left[\begin{array}{l}
\Gamma_{10} \\
\Gamma_{20}
\end{array}\right] \Gamma_{i}=\left[\begin{array}{ll}
\gamma_{11}^{(i)} & \gamma_{12}^{(i)} \\
\gamma_{21}^{(i)} & \gamma_{22}^{(i)}
\end{array}\right] \mu_{t}=\left[\begin{array}{l}
\mu_{1 t} \\
\mu_{2 t}
\end{array}\right] \\
& (i=1,2, \cdots p)
\end{aligned}
$$

$\mu_{1 t}$ and $\mu_{2 t}$ respectively stands for the structural shocks on $\ln (\mathrm{URBDP})$ and $\ln$ (ESHARE3), namely, the structured disturbance term $\mu_{t} \sim \operatorname{VMN}\left(O_{k}, I_{k}\right)$. If $B_{0}$ is invertible, the structured Eq. (7) can be transferred to a reduced-form one:

$$
A \varepsilon_{t}=B \mu_{t}
$$

$A$ and $B$ are the estimated parameter matrix with short-term constraint form. Generally speaking, reduced-form disturbance term $\varepsilon_{t}$ is the linear combination of structured disturbance term, thus standing for a kind of composite shock. There are two endogenous variables in this model. So, it needs to exert $k(k-1) / 2=1$ short-term constraints to make Expression (7) meet recognizable condition. That is to say, service employment absorption capacity cannot exert any influence to the change of current urbanization, namely, $b_{12}=0$.

In order to avoid severe fluctuation of various data, we also test elasticity coefficient among variables. The first step is to logarithmize each time-series variable, and the new sequences are respectively marked as ESERVICE and LNURBDP. Testing through the lag length criteria of independent variables is to give 2 as the largest lag intervals for endogenous variables. Through doing unit root test to the above three variables, we found that these three time-series data have relative stability, thus being able to establish the above SVAR(2) model.

\section{The result of testing}

If model (7) meets the recognizable condition, we can estimate and get all the unknown parameters of the above SVAR model by the full information maximum likelihood (FIML) method and then get the linear combination of matrix $B_{0}, \varepsilon_{t}$, and $\mu_{t}$. So, the specific result is: 


$$
\hat{B}_{0} \varepsilon_{t}=\left[\begin{array}{cc}
1 & 0 \\
0.21 & 1
\end{array}\right]\left[\begin{array}{l}
\varepsilon_{1 t} \\
\varepsilon_{2 t}
\end{array}\right]=\left[\begin{array}{l}
\mu_{1 t} \\
\mu_{2 t}
\end{array}\right]
$$

or expressed as:

$$
\begin{aligned}
& \varepsilon_{1 t}=\mu_{1 t} \\
& \varepsilon_{2 t}=0.21 \varepsilon_{1 t}+\mu_{2 t}
\end{aligned}
$$

The combination of Eqs. (7) and (9) shows that China's urbanization has positive influence to the improvement of service employment absorption capacity when there exists structural shocks. However, further information, after doing Granger causality test to these two variables, shows that China's urbanization is not the Granger cause for the improvement of service employment absorption capacity when given 2 as the largest lag intervals for endogenous.

\section{Further analysis to empirical conclusions}

\section{Internal mechanism analysis to China's urbanization having not significantly improved service employment absorption capacity}

The expansion of urban land area is the main form of China's urbanization, which did not advance traditional cities' transformation and upgrading through the co-evolution of urban and industrial development. And, the expansion of urban land area is the result of achieving industrial surpassing for local government of all levels under the performance evaluation system of GDP. In order to promote the GDP increasing rapidly, undertaking manufacturing transfer and developing the real estate are taken as the shortcuts to realize local economic surpassing. And, industrial new city construction is the best strategy for local government of all levels to undertake manufacturing transfer and develop the real estate (Jiang and Li 2004).

The stereotyped industrial new city construction conducted by the local government has led to blind expansion of cities and imbalanced industrial development, which is mainly expressed as the following three aspects: first, industrial park clusters and local government depend on preferential policies to undertake industrial transfer, which is easy to repeat the low level industrial development and assimilate local industry structure. Second, industrial new cities have been expanded too rapidly, and the competition of local government undertaking industrial transfer is increasingly fierce. Especially, in post financial crisis era, the re-industrialization strategy of developed countries updated the scale and structure of the world's industrial transfer, and many newly built industrial cities have stayed as empty with little business activities. Third, industrial new cities have been expanded too rapidly, while it is very difficult, in short time, to eliminate various institutional barriers of restricting rural surplus labor's migration into cities for settlements, and also, many newly built industrial cities are in such situation with no supporting industry.

China's urbanization, taking industrial new cities as the main way, for one thing, pays too much attention on undertaking the low-end manufacture industries, while the producer services are endogenously less developed. For another, it is also very difficult to attract industrial labor's gathering into such new cities, lacking development space for consumer services, due to institutional barriers and livable contrast between new and old cities. 
International experience comparison of improving service employment absorption capacity through traditional urban transformation and upgrading

For China, stepping into the circle of the world's developed countries requires about $65 \%$ proportion of service employment absorption, $10 \%$ of agricultural employees, and keeping about $25 \%$ for industrial employees. That is to say, maintaining the employment proportion of three industry structures as 1:2.5:6.5 is well in line with China's actual conditions and the evolution law of the world's industry. Standing on this proportion, if the sum of employees is kept unchanged, it still needs to transfer about 190 million rural labors from the primary industry and 30 million manufacturing employees from the secondary industry, namely, the net increase of service employees being 220 million.

If urbanization is measured by the proportion of urban population, developed countries' average urbanization accounts for $70 \%$ or so, China's $53 \%$. Being in line with the level of developed countries, for China, needs about 0.4 billion urban population. If estimated by employees taking up $56.72 \%$ of the total population, China's urbanization can absorb about 0.227 billion employees, revealing that China's urbanization can completely coordinate with service development scale.

Now, the problem is how to allocate the 0.22 billion service employees in the course of China's urbanization, emphasizing on the large-scale construction of industrial new cities or on the developing modern services to lead China's cities' transformation. Compared internationally based on the proportion of service employees, in 2013, China's service employment density is 0.41 , while the average density is 0.74 in developed countries and regions, such as America, the UK, Canada, Japan, German, France, Singapore, Korea, and Taiwan of China. In China, the proportion of city groups with more than 1 million population is $22 \%$, while that of America, the UK, Canada, Korea, Brazil, Japan, France, and Australia is 48, 26, $44,47,40,51,23$, and $60 \%$, respectively, which reveals that it is not necessary for China to emphasize large-scale construction of industrial new cities but to increase the service employment density of current cities.

\section{Main conclusions and policy implication}

The process of China's urbanization featured by industrial new city construction is significantly faster than that of China's industrial restructuring, mainly presenting on the process of urban absorption to service employment being far behind that of industrial new city construction. Such imbalance has caused the serious excess productivity in China's industry, which not only intensified the bottleneck of resources and energy and environment but also relatively lagged the development of producer services and consumer services, thus further restricting the development of China's advanced manufacture industries.

Maybe, it is too early to estimate that services will become the driving force to boost China's economy, but the experience of the economic growth in developed countries shows that economic growth in post industry era depends on the benign interactions between modern services and advanced manufacture. In post industry era, production and consumption basically featured in manufacturing servitization or production servitization and human society will fully step into the era of service economy. Now, China is being in the transformation period from industrialization mid-term stage to mid-and-late stage, the time of service economy is coming, and finally, modern services will also become the main driving force to the future economic growth. 
Cities are the best home for modern services. The advantage of location and industry is embodied in the gathering of productive factor of modern services to cities, especially to large- and medium-sized cities. Essentially, urbanization process is the gathering process of industrial employees to cities. Generally speaking, China's rapid urbanization did not remarkably promote the service transformation of China's industrial structure. Especially, in the east coastal area, urbanization has almost divorced from service gathering. Beside the expansion of industrial new city area, what is more noteworthy is that the service employment density in China's current large- and medium-sized cities is far behind the average level of that in developed countries and regions.

How do we adjust the developing strategy of China's urbanization from policy level to conduct top-level design on urbanization planning? The policy implication studied in this paper is to strictly control the scale of industrial new city construction to increase service labor productivity, improve service employment absorption capacity, raise urban service employment density leading to urban function transformation, and promote the coordinative development between advanced manufacturing and modern services, thus realizing industrial structure upgrading and building an updated China's economy.

In short, China's urbanization is definitely not the "great leap" of industrial new city construction but to position urban function and comprehensively consider the mutual promotion between urban function transformation and modern service development. Hence, urbanization is used to promote city quality and service employment absorption to drive the transformation and upgrading of industry structure finally.

\section{Discussion}

In the empirical part of this paper, the relationship between the process of urbanization and serviceemployment is simply explained by the SVAR model and Granger causality test. Due to the lack of timeseries data of China's service industries, the relationship between knowledge intensive service industryemployment and urbanization has not been specifically regarded. Therefore, taking the knowledgeintensive service industry employment as dependent variable, the urbanization rate as the main explanatoryvariables to study the interaction between the two, it may further confirm the main conclusion of this paper.

\footnotetext{
Authors' contributions

$\mathrm{J}-\mathrm{CX}$ has provided research data and is involved in the writing and discussion of the draft. S-HZ is responsible for writing the main part of this article. Both authors read and approved the final manuscript.
}

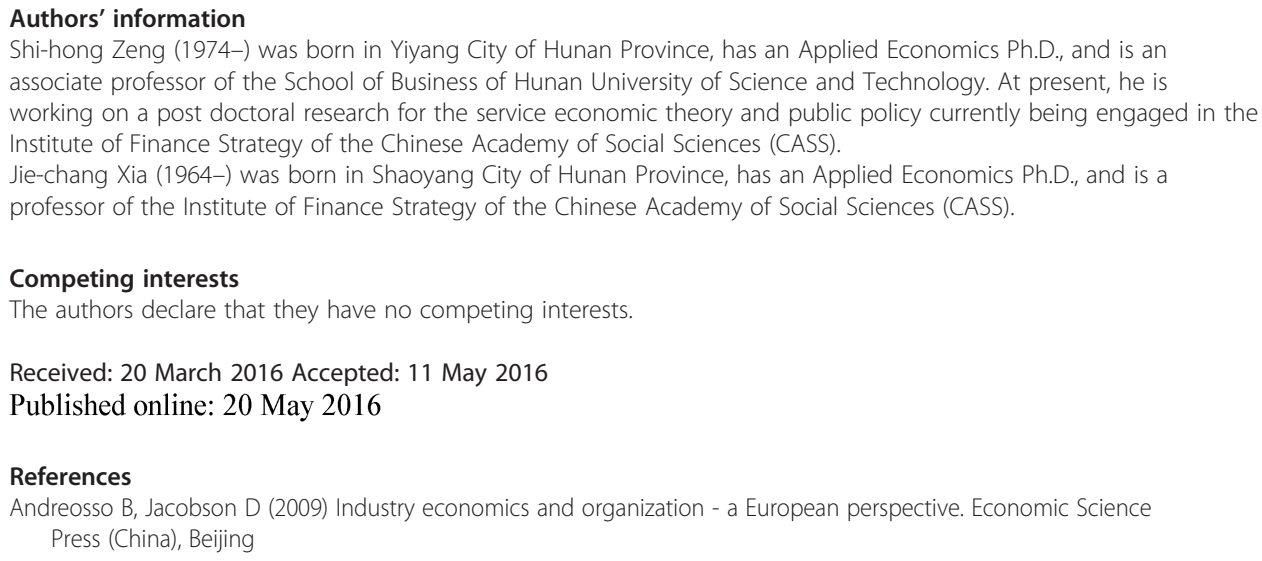


Audretsch D et al (2011) Who's got the aces up his sleeve? Functional specialization of cities and entrepreneurship. Annual Reg Sci 46:621-636

Baumol WJ (1967) Macroeconomics of unbalanced growth: the anatomy of urban crisis. Am Econ Rev 57(No. 3):415-426 Huallacháin BÓ (1989) Agglomeration of services in American metropolitan areas. Growth Chang 2:35-51

Francisco J, Kaboski JP (2012) The rise of the service economy. Am Econ Rev 102(No. 6):2540-2569

Gao T (2005) The employment and example of methods of econometric analysis and demonstration modeling. Tsinghua University Press (China), Beijing

He D, Yao Z, Cheng J (2009) Empirical analysis on the influencing factor of China's service employment. Econ Financ Trade (China) No. 8:99-107

Hu Y, Li Z, Mao S (2010) Empirical analysis about the influence of China's urbanization on services_facts, paradox, and explanation. Contemp Manager (China) No. 11:44-49

Jiang X, Li H (2004) Services and Chinese economy: correlation and potential of promoting growth. Econ Res (China) No. 1:4-15

Li G (2013) Can services be the motive industry of China's economy? China Ind Econ (China) No. 4:43-56

Li J, Qian C (2007) The spatial distribution characteristics of services and correlation analysis with urbanization-take Zhejiang Province as a sample. Zhejiang Acad J (China) No. 1:172-177

Liang D, Zhang G (2013) Determinant to the proportion of service employment: restudy on "Baumol-Fox" model. Nanjing Soc Sci (China) No. 8:16-23

Liu W (2007) Study on the correlation between China's services and urbanization. Beijing Polytec Univ (China) No. 6:20-24 Michaels G, Rauch F, Redding SJ (2012) Urbanization and structural transformation. Q J Econ 127:535-586

Yang X (2003) Economics: new classical versus neoclassical frameworks. Social Sciences Academic Press (China), Beijing

Zhang Y, Yongjian P, Litai C (2013) Urbanization and services gathering-based on the view of systematic coupling interaction. China Ind Econ (China) No. 6:57-69

Zeng S, Xiang G (2013) High profitability of technology-based services: market power or innovation dividend-the impacts of structural tax cuts and coordinative innovation on technology-based service innovation. Econ Financ Trade (China) No. 10:118-126

\section{Submit your manuscript to a SpringerOpen ${ }^{\circ}$} journal and benefit from:

- Convenient online submission

- Rigorous peer review

- Immediate publication on acceptance

- Open access: articles freely available online

- High visibility within the field

Retaining the copyright to your article 